\title{
Non-Linear Analysis of Concrete Deep Beams Reinforced with FRP
}

\author{
Fawzi Latosh, Alireza Torkman Rashid, Ashutosh Bagchi \\ Concordia University \\ Montreal, Canada \\ falatosh@hotmail.com; a_torka@encs.concordia.ca; ashutosh.bagchi@concordia.ca
}

\begin{abstract}
Deep beams are the elements that have applications in many structures such as pile caps, girders, foundation walls and offshore structures. The behaviour of deep beams is mostly affected by its depth-span ration, type of reinforcements, materials used in the concrete. Since the behaviour of deep beams are different than the traditional beams, a few conventional methods has been introduced to model these types of beams such as empirical equations or strut and tie model (STM). However, there is a lack of study on the modelling and designing deep beams reinforced with the FRP reinforcement in the conventional methods. In this paper four deep beams reinforced internally with GFRP has been modelled experimentally and numerically. The behaviour of the beam has been recorded during the experiment and it has been compared with a non-linear numerical model to verify the results. The results of the ultimate loads, and load- deflection of the beams has been compared and verified.
\end{abstract}

Keywords: GFRP, Deep Beam, Finite Element Analysis, FRP Reinforcement.

\section{Introduction}

The applications of the deep beams are included in variety of structures, and therefore they are an important element that are needed to be studied. In addition, the behaviour of deep beams has differences than the slender (shallow) RC beams. The strength of these types of beams is more dependent on the a/d (Shear Span/Depth) ratio. Therefore, other methods has been introduced for modelling and designs of such beams [1].

Meanwhile, steel reinforcement are susceptible to corrosion which would result in cracking of the concrete thus shortening the lifespan and eventually the failure of the beam. Compared to conventional steel reinforcements, FiberReinforced Polymer (FRP) are corrosion free and light materials and could be used as an efficient alternative for the steel reinforcements. Many studies have shown the benefits of FRPs in the application of the concrete elements, but, there is still a lack of research on the behaviour of the FRP in deep beams.

The prediction of behaviour of deep beams with use of the codes is not efficient since, in the codes the non-linear behaviour of the beams has been neglected hence they fail to provide information regarding the serviceability of such beams [2]. The cracks occurred in the concrete and the yielding of the steel are important feature which are the results of the non-linear behaviour [e]. These are needed to be heeded at while designing a concrete structure. Consequently the need of a finite element analysis model that is verified is essential [4]. Finite Element can provide authenticated models of concrete structure that are in good accordance to the real models. Therefore, a reliable FE model could be of great use in the design and model of the deep beams.

The purpose of this study was to evaluate the results of the experimental and the solution of FE models are concurred. Hence, demonstrating the application of finite element in modelling the FRP deep beams for future studies of their behaviour instead of using the expensive experimental methods.

\section{Experimental Procedure}

\subsection{Features of the Specimens}

Four different concrete deep beams were tested in order to differentiate the effects of the web reinforcements and the shear span over depth ratio. The first group of the beams are with the shear span to depth ratio of $a / d=1$ and two different web FRP reinforcement of $\rho_{w}=0,100 \%$, where $\rho_{w}=100 \%$ indicated the maximum allowable of the spacing in the web reinforcements to control cracking in the concrete beams. The second group consists of shear span to depth ration $a / d=2$ and the web reinforcements of $\rho_{w}=0,100 \%$. the beams were tested to failure under three points loading. 
For the design of the beams the anchorage length, the web reinforcement requirements and main reinforcement ratio were considered. The beams consist of the same width of $230 \mathrm{~mm}$ and a total span length of $1800 \mathrm{~mm}$. In order to obtain different shear span to depth ratio, different heights 328 and $600 \mathrm{~mm}$ were chosen.

The FRP type that is used for this experiment is the GFRP bars that are most common material used in the industry. Each group consist of main longitudinal GFRP ratio of $\rho=1$ to 1.197 percent and web reinforcements of $6 \mathrm{~mm}$ diameters. The bearing plates of $230 \times 180 \times 30 \mathrm{~mm}$ was used for the loading points and the supports. Details of the specimens are shown in the table 1 and figure 1.

Table 1: Features of the specimens.

\begin{tabular}{|c|c|c|c|c|c|c|c|c|c|c|}
\hline Specimen & $\boldsymbol{f}_{\boldsymbol{c}}^{\prime}(\boldsymbol{M P a})$ & $\boldsymbol{b}(\boldsymbol{m m})$ & $\boldsymbol{d}(\boldsymbol{m m})$ & $\boldsymbol{L}_{\boldsymbol{e}}(\boldsymbol{m m})$ & $\boldsymbol{a} / \boldsymbol{d}$ & $\begin{array}{c}\text { Main } \\
\text { Reinforcements }\end{array}$ & $\boldsymbol{f}_{\boldsymbol{f u}}$ & $\boldsymbol{\varepsilon}_{\boldsymbol{f u}}$ & $\boldsymbol{\rho}(\%)$ & $\boldsymbol{\rho}_{\boldsymbol{v}}(\%)$ \\
\hline $\mathrm{A} 1 / 100$ & 49.8 & 230 & 621 & 1240 & 1 & $6 \# 6(19 \mathrm{~mm})$ & 656 & 0.0153 & 1.197 & 0.141 \\
\hline $\mathrm{A} 1 / 50$ & 52.7 & 230 & 621 & 1240 & 1 & $6 \# 6(19 \mathrm{~mm})$ & 656 & 0.0153 & 1.197 & 0.061 \\
\hline $\mathrm{C} 1 / 100$ & 50.8 & 230 & 328 & 1310 & 2 & $6 \# 4(13 \mathrm{~mm})$ & 708 & 0.0170 & 1 & 0.158 \\
\hline $\mathrm{C} 1 / 50$ & 51.3 & 230 & 328 & 1310 & 2 & $6 \# 4(13 \mathrm{~mm})$ & 708 & 0.0170 & 1 & 0.061 \\
\hline
\end{tabular}
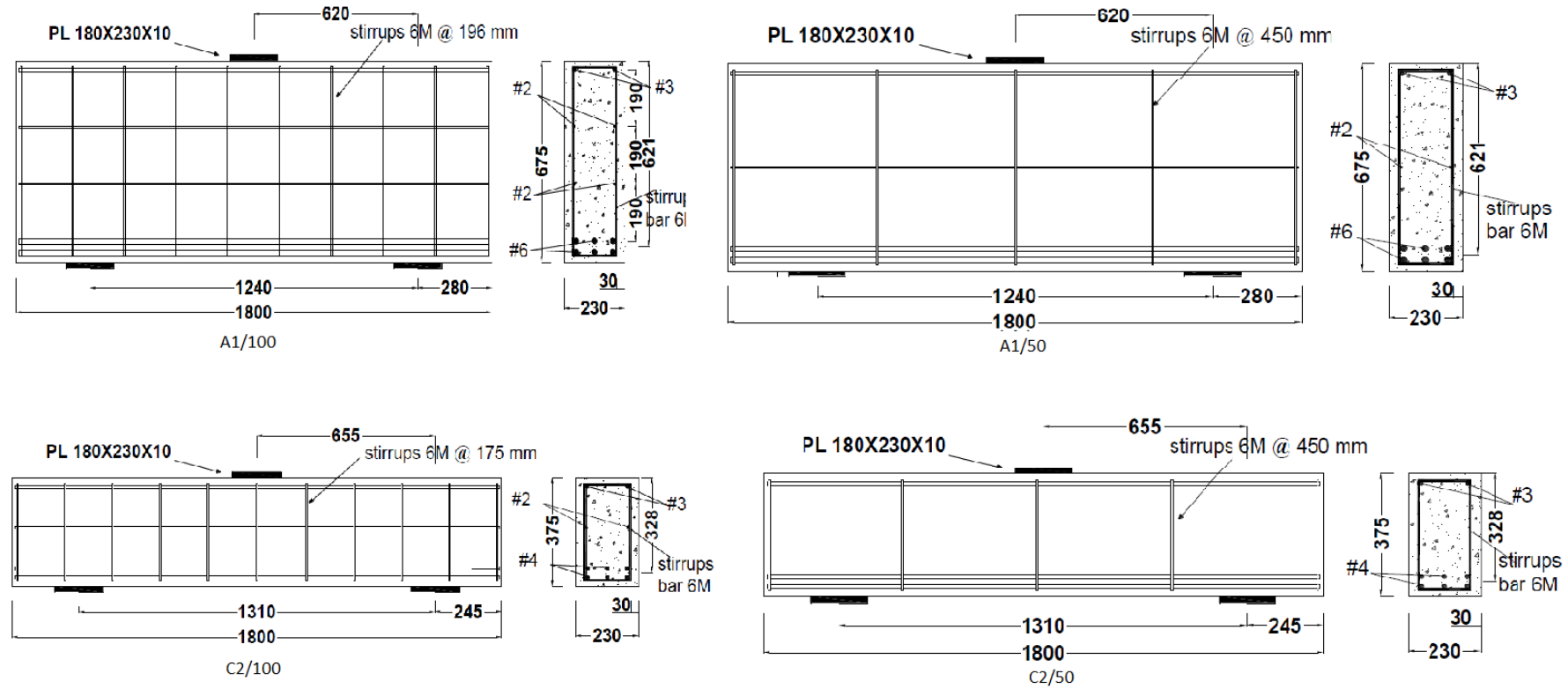

Fig. 1: Test setup and Specimen geometry.

\subsection{Test Procedure}

The test specimens were simply supported and were set to failure under three points loading. A maximum load of $2000 \mathrm{KN}$ was applied on the mid span of the beams using an actuator on the bearing plates. Meanwhile, steel roller constraint were used in order to achieve the simple support in the horizontal direction. Two potentiometers were used in order to measure the deflection in the mid span. In addition, multiple of strain gauges were installed on the GFRP bars for monitoring the strain of the reinforcements.

\section{Numerical Analysis}

Finite Element Method is a well-known numerical analysis for simulation and modelling of concrete beams. Thus, for the purpose of finding a reliable model for analysis and design of the deep beams reinforced with FRP bars, in this study, a model of FE has been developed and the results were compared with the experimental one. 


\subsection{The FE Model}

\subsubsection{Concrete Property}

For modelling the non-linearity of the concrete, in this study the method of damaged plasticity of concrete was used to achieve non-linear behaviour. The properties of the used concrete was with a $f_{c}^{\prime}=35 \mathrm{MPa}$ and a Poisson's ratio of 0.15 .

\subsubsection{GFRP Property}

The GFRPs were modelled using elastic isotropic materials with the features shown in table 2.

Table 2: The Properties of the GFRP.

\begin{tabular}{|c|c|c|c|c|c|c|}
\hline Rebar & $\begin{array}{c}\text { Diameter } \\
(\mathbf{m m})\end{array}$ & Area $\left(\mathbf{m m}^{\mathbf{2}}\right)$ & $\begin{array}{c}\text { Tensile } \\
\text { Modulus of } \\
\text { Elasticity } \\
(\mathbf{G P a})\end{array}$ & $\begin{array}{c}\text { Ultimate } \\
\text { Tensile } \\
\text { Strength } \\
(\mathbf{G P a})\end{array}$ & $\begin{array}{c}\text { Ultimate } \\
\text { Strain in } \\
\text { Tension }(\%)\end{array}$ & $\begin{array}{c}\text { Poisson's } \\
\text { Ratio }\end{array}$ \\
\hline$\# 6$ & 6.350 & 31.7 & 46.1 & 874 & 1.90 & 0.25 \\
\hline$\# 10$ & 9.525 & 71.3 & 45.4 & 856 & 1.89 & 0.21 \\
\hline$\# 13$ & 12.700 & 126.7 & 46.3 & 708 & 1.70 & 0.26 \\
\hline$\# 19$ & 19.050 & 285 & 47.6 & 656 & 1.53 & 0.25 \\
\hline
\end{tabular}

\subsubsection{Element Types}

The concrete element is modelled using a solid 3-dimensional element in order to display the non-linear behaviour of the concrete. The mesh that has been used for the concrete is C3D8R which stand for an 8 node linear brick with reduced integration and hourglass control. And as for the GFRPs, the truss element is used since the bars are only used to transfer normal forces. The mesh type chosen for the reinforcements is T3D2 which stands for 3 dimensional 2 node with first order integration truss element. Eventually, the same size of mesh has been used in order to ensure that the interactions of the different types of materials are fully connected. Thus, the parts have been chosen to be independent in the model in order to demonstrate a better interaction between the concert and FRP reinforcements. Figure 2 displays the mesh of A1/100 beam. For the purpose of applying load and defining the supports, three partition has been defined to demonstrate the location of load bearing and supports. The load that has been applied to the beams has been defined using a pressure load with equally spaced time steps to simulate the load of the actuator on the beams. In addition, at the locations of the supports, a pinned boundary condition has been introduced to constrain the beam only in the $\mathrm{x}, \mathrm{y}$, and $\mathrm{z}$ directions. For demonstrating the non-linear behaviour of the beam a dynamic-implicit method has been defined with time steps of 0.01 sec. To model the interactions between the reinforcements and concrete, the embedded region interaction has been defined. It has been assumed that the concrete and reinforcements have complete contact with one another.

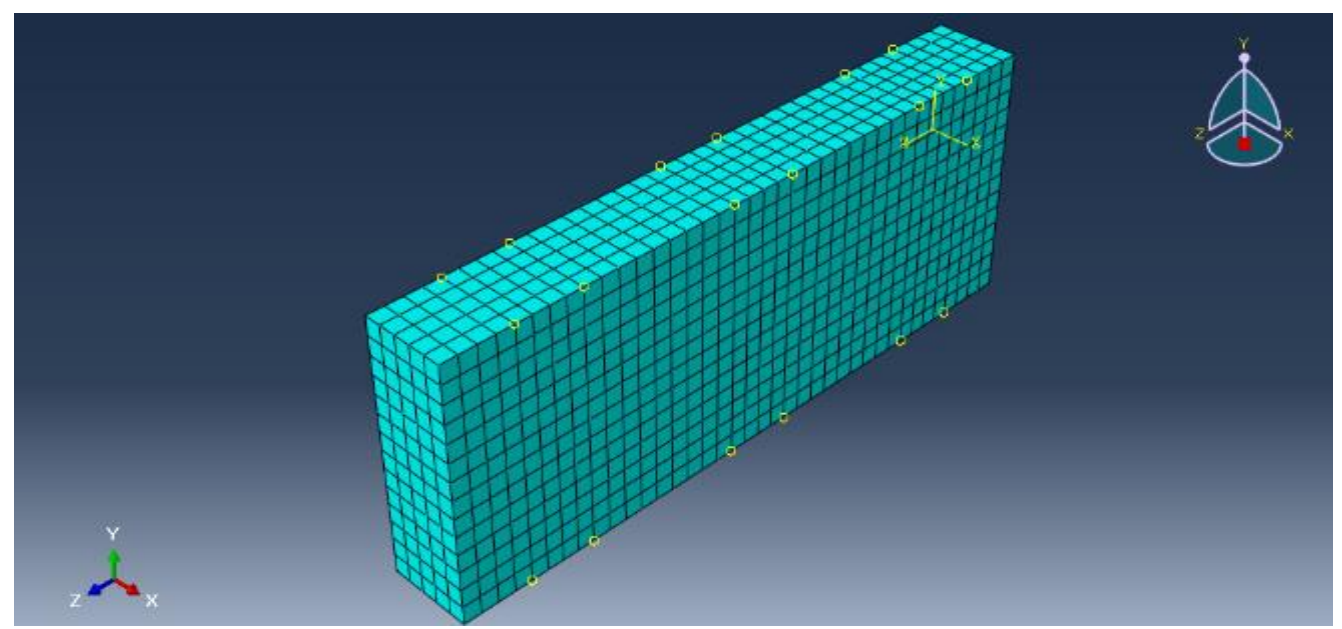

Fig. 2: The Mesh of A1/100. 


\section{Comparison of Numerical Analysis and Experimental Results}

In order to verify the FE model and achieve a reliable Finite Element model, the results of the experiment and the FE was compared to one another. For this purpose the displacement in the mid span of the beams and the ultimate load have been studied. Figures 3 to 6 show the displacement of the mid span of the beams and table 3 demonstrated the ultimate loads acquired from the experiment and the ratio of the experimental results and the FE model.

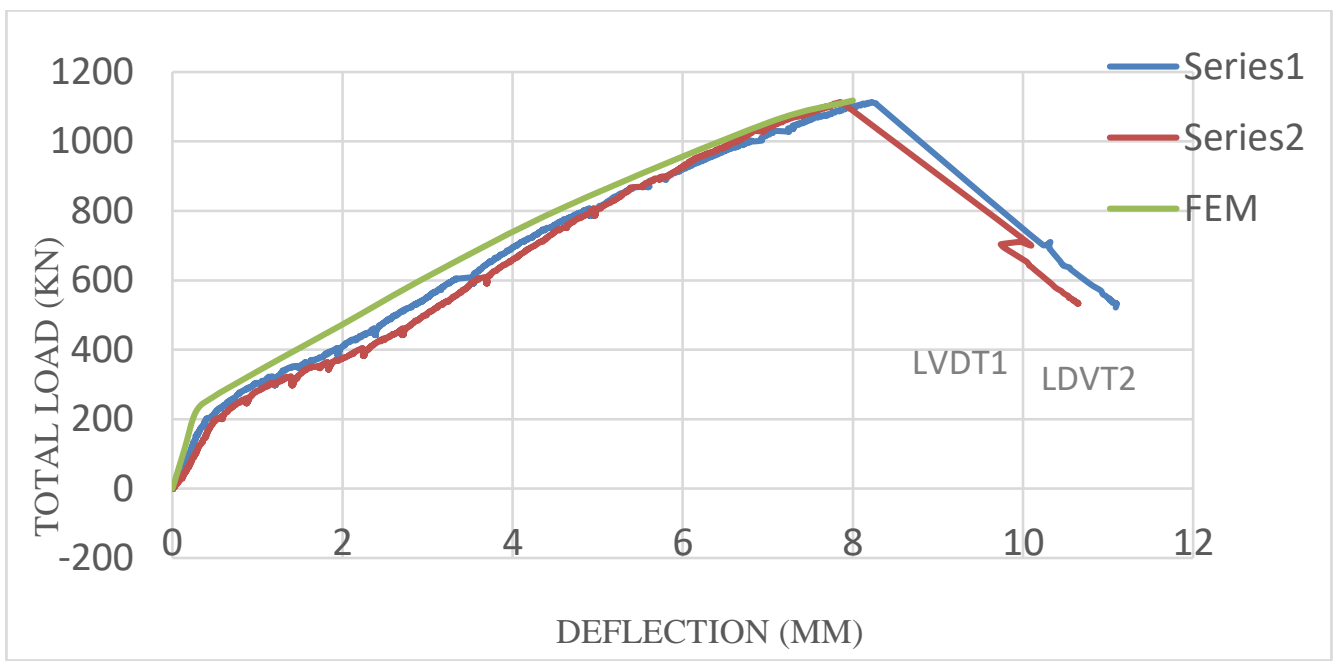

Fig. 3: Deflection of Mid Span of A1/100.

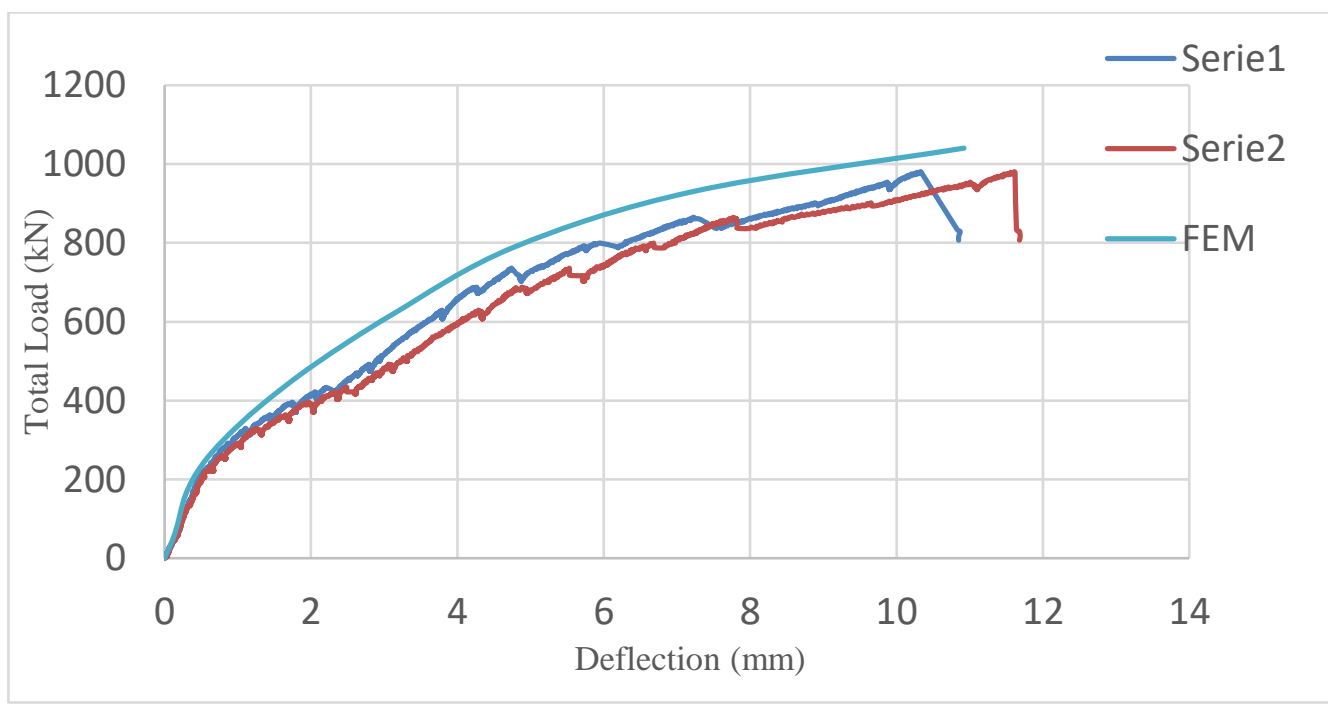

Fig. 4: Deflection of Mid Span of A1/50. 


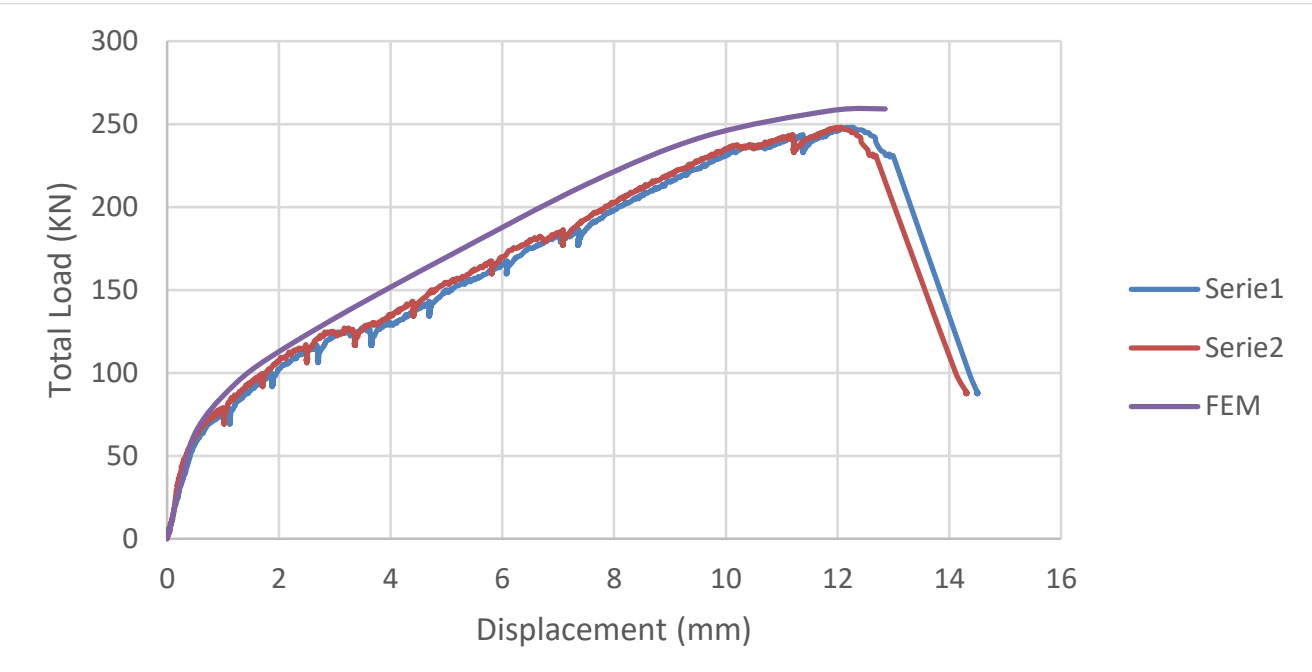

Fig. 5: Deflection of Mid Span of C2/100.

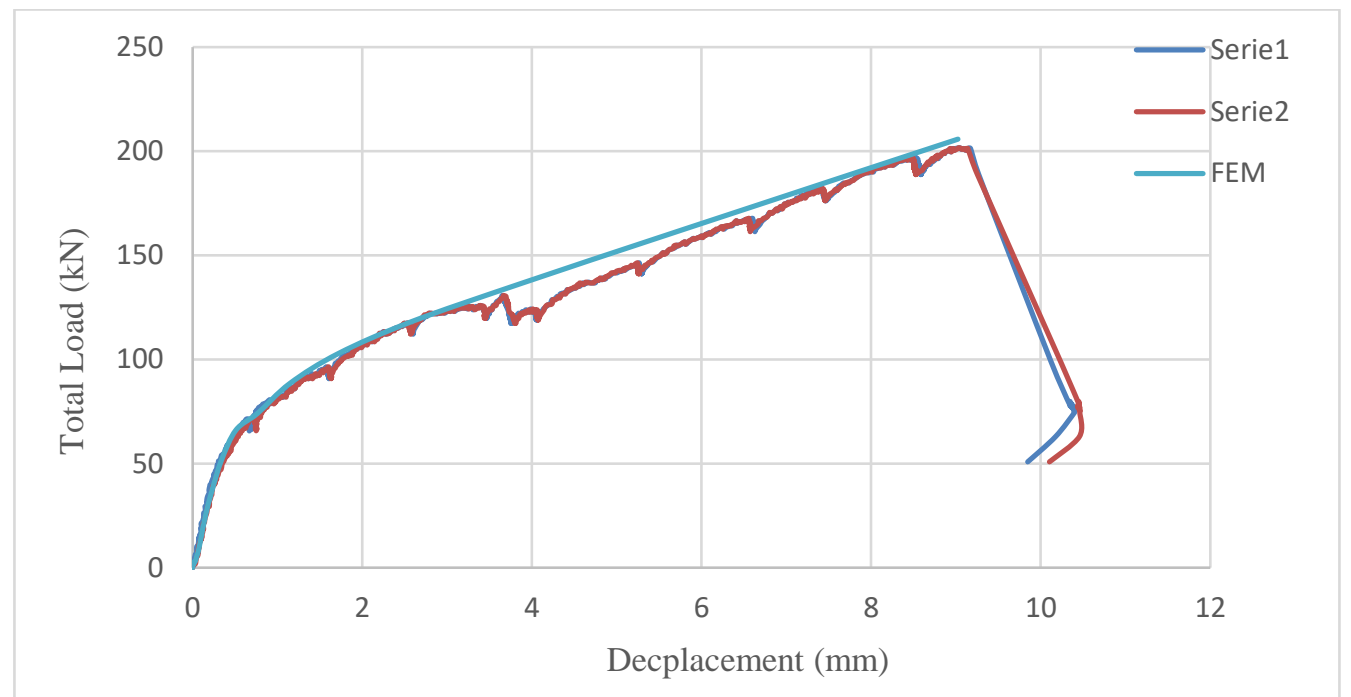

Fig. 6: Deflection of Mid Span of C2/50.

Table 3: The Experimental and FEM Results.

\begin{tabular}{|c|c|c|c|c|}
\hline \multirow{2}{*}{ Specimen } & \multicolumn{2}{|c|}{ Experimental Results } & \multicolumn{2}{c|}{ Experimental/FE Results } \\
\cline { 2 - 5 } & Strut Cracking Load (KN) & $\begin{array}{c}\text { Displacement } \\
(\mathbf{m m})\end{array}$ & Strut Cracking Load & Displacement \\
\hline $\mathrm{A} 1 / 100$ & 192.05 & 8.22 & 0.87 & 1.01 \\
\hline $\mathrm{A} 1 / 50$ & 193.5 & 10.33 & 0.96 & 0.95 \\
\hline $\mathrm{C} 2 / 100$ & 60.62 & 12.04 & 1.04 & 0.94 \\
\hline $\mathrm{C} 2 / 50$ & 69.27 & 9.12 & 1.05 & 1.01 \\
\hline
\end{tabular}

\section{Conclusion}

In this study, the deep beams have been modelled using both experimental and Finite Element Method. Base on the obtained results, it can be inferred that the FEM model could perfectly predict the behaviour of concrete deep beams reinforced with FRP bars. Based on the results of the maximum load that the first crack would occur, it is shown that the 
results have the maximum of 5 percent difference. This difference could be based on the ignoring some variables that might have happened during the experiment which could not be considered in the finite element method. And also, since Finite Element is a numerical method and is considered an approximation, there are some small errors that could be neglected. In conclusion, it was demonstrated that FEM could be used in order to achieve reliable models for the deep beams and to predict their behaviour.

\section{References}

[1] A. K. El-Sayed, E. F. El-Salakawy, and B. Benmokrane, "Shear capacity of high-strength concrete beams reinforced with FRP bars," ACI Structural Journal, vol. 103, no. 3, pp. 383, 2006.

[2] ACI Committee, American Concrete Institute, and International Organization for Standardization, "Building code requirements for structural concrete (ACI 318-08) and commentary," American Concrete Institute, 2008.

[3] S. M. Shahidul Islam, and Amar Khennane, "Experimental verification of automated design of reinforced concrete deep beams," SIMULIA Customer Conference, 2012.

[4] J. I. Enem, et al, "Analysis of deep beam using Finite Element Method," International Journal of Applied Science and Engineering Research, vol. 1, no. 2, pp. 348-356, 2012. 